\title{
Model Test on Mechanical Properties of Glass Fiber Reinforced Plastic Mortar Pipes Culvert Under High Embankment
}

\author{
Huawang Shi ${ }^{\mathrm{a}, \mathrm{b},{ }^{*}}$, Hang Yin ${ }^{\mathrm{a}}$, and Lianyu $\mathrm{Wei}^{\mathrm{b}}$ \\ ${ }^{a}$ Hebei University of Engineering, Handan, 056038, China \\ ${ }^{b}$ Hebei University of Technology, Tianjin, 300401, China
}

\begin{abstract}
Glass fiber reinforced plastic mortar pipes is a new type of composite material. In order to obtain the design and construction parameters and to detect the cracking reason for the glass fiber reinforced plastic mortar pipes (FRPM) culvert with high filling, model test on mechanical properties of FRPM culvert was performed. The results show that the deformation laws of circumferential tension or compression are consistent, with the increase of filling height, the growth of stress in FRPM and vertical soil pressure are nonlinear. Simulation of the maximum filling height of $12 \mathrm{~m}$, under axial loading, the circumferential stress and strain values of culvert are $6770 \mathrm{kPa}$ and $2109(\varepsilon) /\left(\times 10^{-6}\right)$; the maximum soil pressure occurred at the top of the culvert, the value is $322 \mathrm{kPa}$; under eccentric loading, the maximum values of circumferential stresses and strain are $6092 \mathrm{kPa}$ and $1898(\varepsilon) /\left(\times 10^{-6}\right)$; the maximum value of soil pressure is $183 \mathrm{kPa}$.
\end{abstract}

Keywords: highway engineering; mechanical properties; model test; glass fiber reinforced plastic mortar pipes (FRPM); culvert

(Submitted on February 26, 2018; First revised on March 28, 2018; Second revised on April 28, 2018; Accepted on May 10, 2018)

(C) 2018 Totem Publisher, Inc. All rights reserved.

\section{Introduction}

Glass Fiber Reinforced Plastic Mortar Pipes (FRPM Pipes or GRP Mortar Pipes) is a new type of composite material produced by a certain process method, which is made of resin as matrix material, glass fiber and its products as reinforcing material and quartz sand as filling material [1,2,3]. According to production process it can be divided into three categories including fixed length winding, centrifugal casting and continuous winding. FRPM Pipes have the advantages of excellent corrosion resistance, good bearing capacity, small resistance, long service life, convenient installation, short construction period and low investment. resist acid, alkali, salt, sea water, untreated sewage, corrosive soil or groundwater, and the erosion of numerous chemical fluids. The service life of the pipe is longer than that of the traditional pipe, and the designed service life is more than 50 years. For FRPM pipes, they are widely used in municipal and municipal transmission and distribution networks. produced by filament winding has a specific gravity of $1.65-2$, only $1 / 4$ of steel, but the hoop tensile strength of FRPM is - 300MPa, the axial tensile strength is between - 60 and $150 \mathrm{MPa}$. Therefore, its specific strength (strength / gravity) is 2-3 times the alloy steel, so that it can according to the different requirements of users, designed to meet all kinds of internal and external pressure requirements of the pipeline. For the same diameter of single FRPM tube, only carbon steel (steel plate) $1 / 2.5,1 / 3.5$ cast iron pipe, prestressed reinforced concrete pipe is about $1 / 8$ [5,6], so the transportation is very convenient for installation. It has been widely used in civil engineering.

The culverts, as the important parts of highway engineering in both the number of projects and the cost of construction, occupy a considerable proportion. Through the investigation of FRPM pipe culvert in service, it can be found that the design and construction methods exist blindness and uncertainty and the deformation and stress characteristics of culvert under the fill load are not clear. Many researches have been carried out on the structural characteristics of glass fiber reinforced plastic sand pipe, but most of them focus on the material properties of FRPM pipe as water pipeline [4,7,8,9]. Jeyapalan et al. [10] reviewed some FRPM engineering examples, discussed the problems in the production and quality control in the construction

* Corresponding author.

E-mail address: 81158626@qq.com 
process, and also summarized some factors that may lead to pipeline failure. The epoxy resin and polyester polymer and fiber reinforced mortar thermal expansion properties were studied by Ribeiro [17]. Del Vecchio et al [7] studied the polymer mortar pattern under monotonic and cyclic loading of the plastic behavior and strain rate sensitivity. Rafiee and Reshadi[18-20] analyzed the glass fiber reinforced plastic mortar pipe under the action of internal hydrostatic pressure failure. Through the static test, the vertical deformation of culvert, deflection and crack of culvert, the overall settlement were measured and analyzed by Jin et al [11]. Wang et al. [21] established the FRPM pipe model by using the finite element software ANSYS, the calculation and test results were compared to determine the feasibility and accuracy of the finite element method. Xu [22] established a complete buried FRPM model for seismic response analysis. The numerical analysis model and the complex interaction between the effect of pipe soil as well as the seismic wave scattering from a finite field to infinite propagation were considered. In these papers mentioned above, the Influencing effects of length, diameter of the pipe, the elastic modulus of the soil around the pipe and the buried depth of the pipe on the seismic response of the buried FRPM pipe were analyzed.

The recent studies of FRPM pipes were mostly investigated the pipeline stress and deformation analysis or simulated FRPM pipes by using finite element method[12-16]. The main aim of this study is to analyze the stress and strain characteristics of FRPM pipe underground and the distributions of loading and earth pressure around the pipe through simulation test technology.

\section{Test description}

\subsection{Manufacture of FRPM pipe specimen}

Glass fiber reinforced plastic sand pipe is made through continuous and cyclic movement of the steel strip before and after the continuous moving of the core mold, and the production process of filament winding, packing compound and quartz sand is sequentially completed. After all the processes are completed, the molding pipe is transported to the curing process to complete the curing. Finally, the required size (with nominal diameter of $1500 \mathrm{~mm}$, nominal thickness of $50 \mathrm{~mm}$, length of $1500 \mathrm{~mm}$ ) is cut in accordance with the experiment standard. The each manufacture process of site is shown in Figure 1.

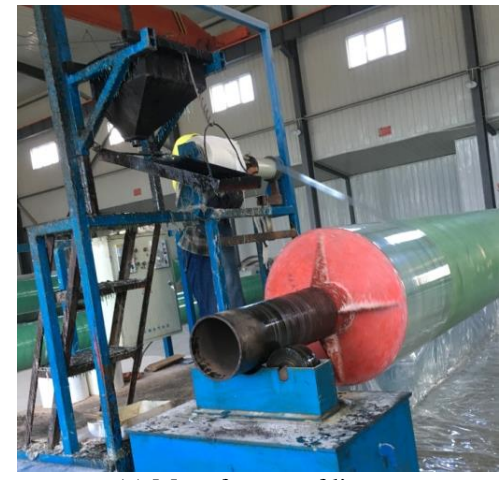

(a) Manufacture of liner

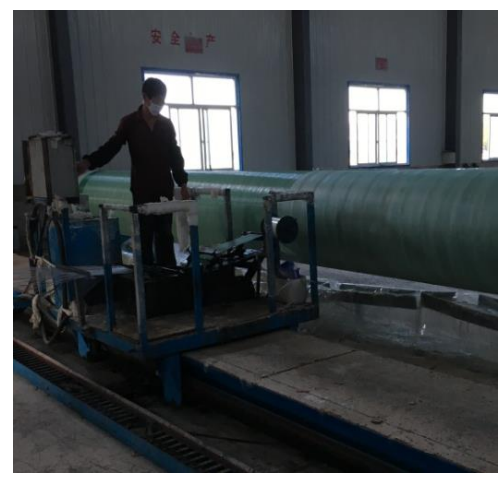

(b) Filament winding

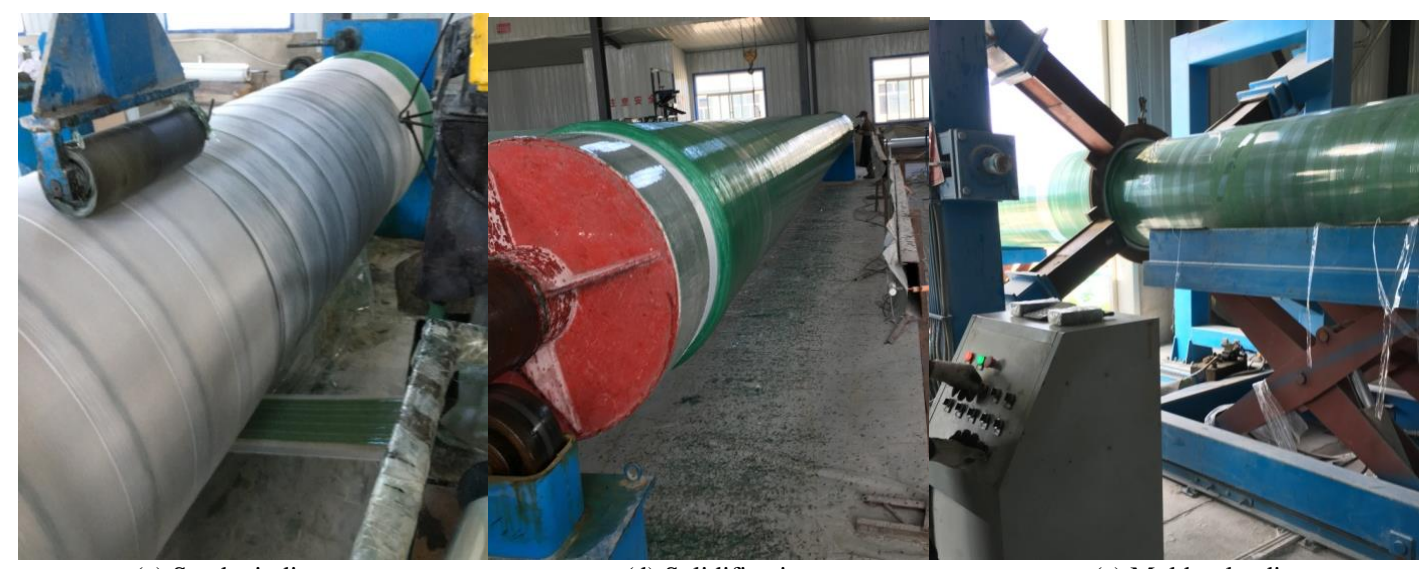

(c) Sand winding

(d) Solidification

(e) Mold unloading

Figure 1. (a) Manufacture of liner (b) Filament winding (c) Sand winding (d) Solidification (e) Mold unloading 


\subsection{Configuration of testing equipment}

In order to simulate highway culvert in field conditions, a model box is made with $3 \mathrm{~m}$ long $2 \mathrm{~m}$ wide, and height $2.40 \mathrm{~m}$. The model box structure is assembled with three rigid channel steel reinforced steel plates, and the other side, which can be removed, is constructed with the organic glass plate with the thickness of $2 \mathrm{~cm}$. The removable organic glass can install displacement observation point in the model, which is to measure and observe the displacement under different filling heights of the model (especially the displacement around the culvert). The diameter of FRPM pipe is $1.5 \mathrm{~m}$, shell thickness is $50 \mathrm{~mm}$ and long is $1.5 \mathrm{~m}$. The culvert backfill project is located on site soil with the properties of the maximum dry density $1.86 \mathrm{KN} / \mathrm{m}$ f and, the optimal water content $12 \%$.

\subsection{Measuring points and gauge}

A total of 16 measuring points are set in the experiment. There are 8 points in each side of the inner and outer of FRPM pipes culvert, which are pasted according to "T" shape of the axial and circumferential directions. The measurement points in the profile are shown in Figure 2 (a). The layout of deformation measuring device is shown in Figure 2(b). Earth pressure measuring points are emplaced on the top, bottom and both sides of the horizontal position of the culvert, as shown in Figure 2(c). The BE120-3AA strain gauge is used in this work.

\subsection{Test loading system}

The loading is the weight of filling with the height range from top of the culvert to the top of test box. When filling reaches the top of the test box, the increased loading is replaced by Jack loading system. Pressure sensor is used to control loading test load. The loading system is composed of steel plate, freely supported beam, Jack, 50t pressure sensor and counter force beam. When plate is loaded, keep the center of steel plate alignment with the test center under load. Then, the hydraulic jack is installed in the loading plate at the center. It is important to ensure coincidence of the pipe culvert center, loading plate center, and force system center, otherwise it will produce eccentric load test process, cause Jack tilt, as well as the difficulty of applying lad. The system is loaded step by step, and the numerical value of each stage is converted into an approximate simulation of the filling height, until the height of the simulated filling is reached. The specific loading device and model test are shown in Figure 3, Figure 4, respectively.

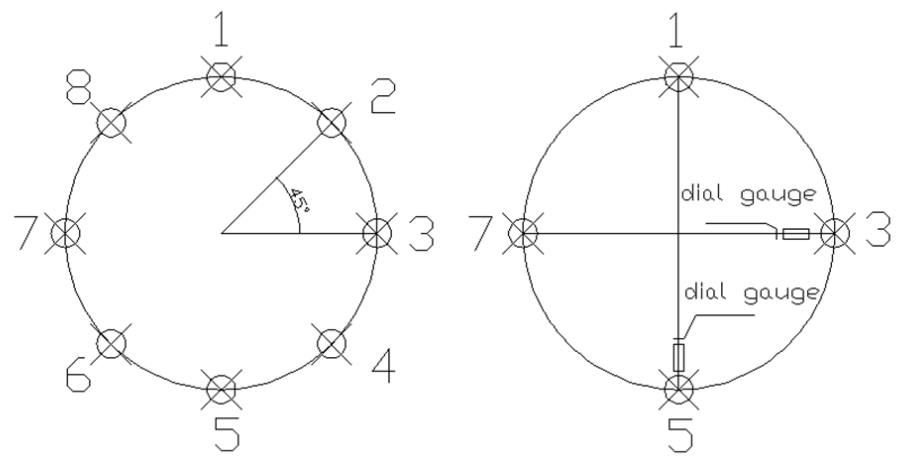

(a) Strain measuring points

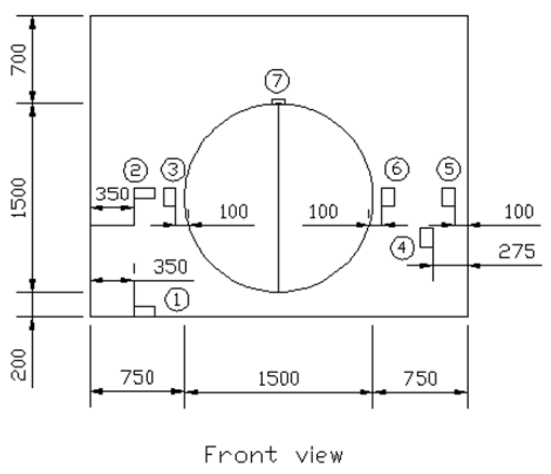

(b) Deformation test system

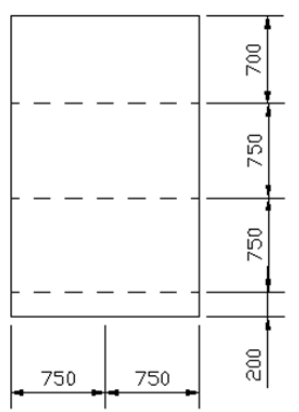

Left view

(c) Soil pressure gauge location

Figure 2. (a) Strain measuring points (b) Deformation test system (c) Soil pressure gauge location 


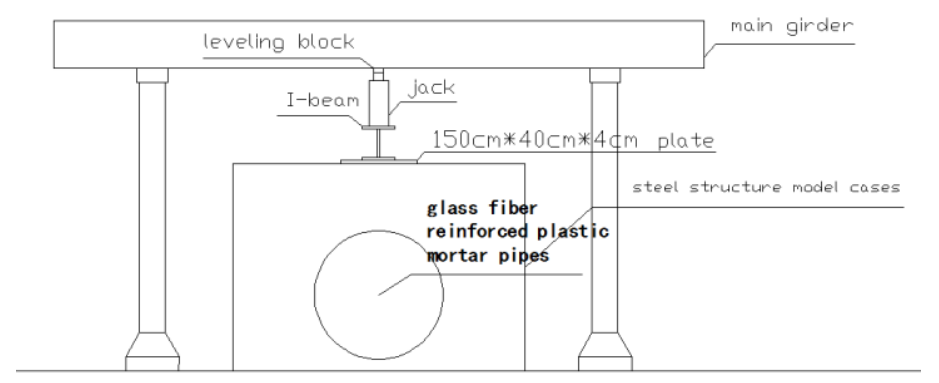

Figure 3. Diagram of loading

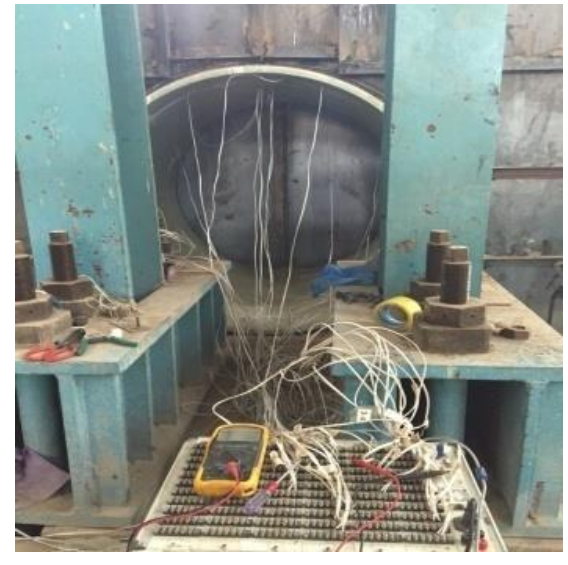

(a) Gauge of strain measurement

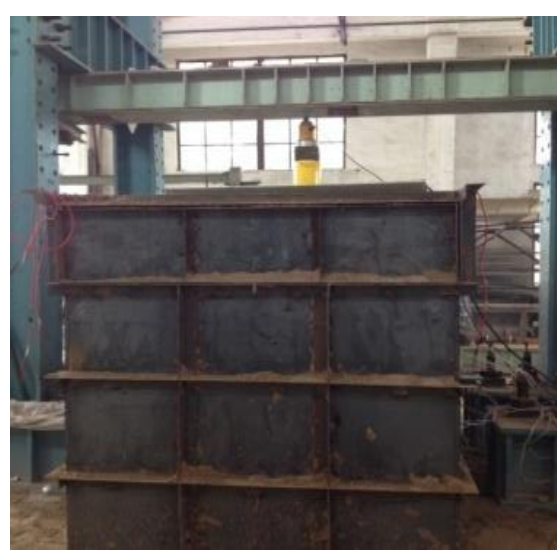

(b) Loading device

Figure 4. (a) Gauge of strain measurement (b) Loading device

\section{Results and discussion}

According to the data obtained from experiment, the change rules of axial and circumferential stresses and strains at the inner and outer sides of the measuring points on the FRPM pipe culvert are basically the same [23]. In the following, therefore, test simulating FRPM pipes culvert under a highway compacted by high fill are conducted to investigate the change rules of stress and strain in the ring direction of FRPM pipe.

\subsection{Stress analysis for inner side of FRPM pipes under axial loading}

The stress and strain change rules of each test point on the inner side of the FRPM pipe culvert is shown in Figure 4(a) and Figure 5. In which, the unit of strain is $(\varepsilon) /\left(\times 10^{-6}\right)$, and the filling height being $\mathrm{m}$. With height of filling increasing, the tangential strain of FRPM pipe culvert presents nonlinear growth trend.

As shown in Figure 4(a), the circumferential stress and strain inside the culvert distribute symmetrically. at the top of culvert inside (point1), the stress and strain values reach maximum, which are $2109 \quad(\varepsilon) /\left(\times 10^{-6}\right)$ and $6770 \mathrm{kPa}$, followed by the measuring points No.5 (at the bottom of pipe culvert) with the values are in the tensile stress state. The measuring points at both ends of the horizontal diameter (points No.3 and No.7) are in compressive stress. The stress at the measurement points of 1/4 height of upper pipe culvert and 1/4 height of the culvert bottom are changing greatly.

It can be seen from Figure 5, the tube at points 1 and 5 withstands tensile stress. Whereas the points 2, 3, and 7 withstand compressive stress (tension is positive, negative pressure). The stresses of measuring point at the upper pipe culvert of $1 / 4$ height and lower the height of the 1/4 change little, which are basically in the transition zone of tensile stress and compressive stress. When the filling height is small (within 3 meters), the circumferential strain and stress are larger. With the increase of filling height, the numerical data increase. At the stage of the small filling height, the initial deformation of the pipe, affected by the construction, culvert compaction, is large, so it needs to be strengthened at this stage. 


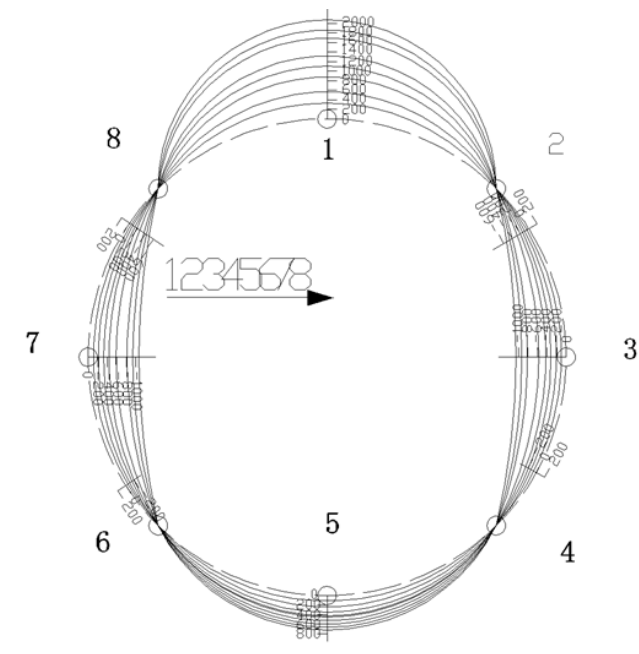

(a) Axial loading

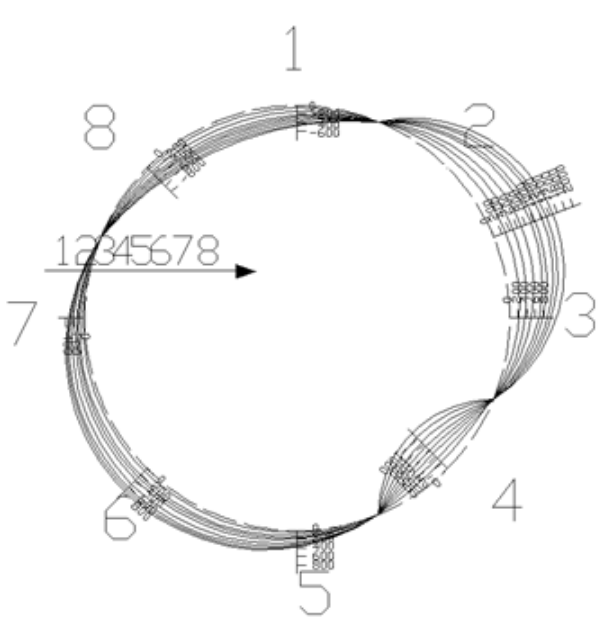

(b) Eccentric loading

Figure 5. (a) Axial loading (b) Eccentric loading

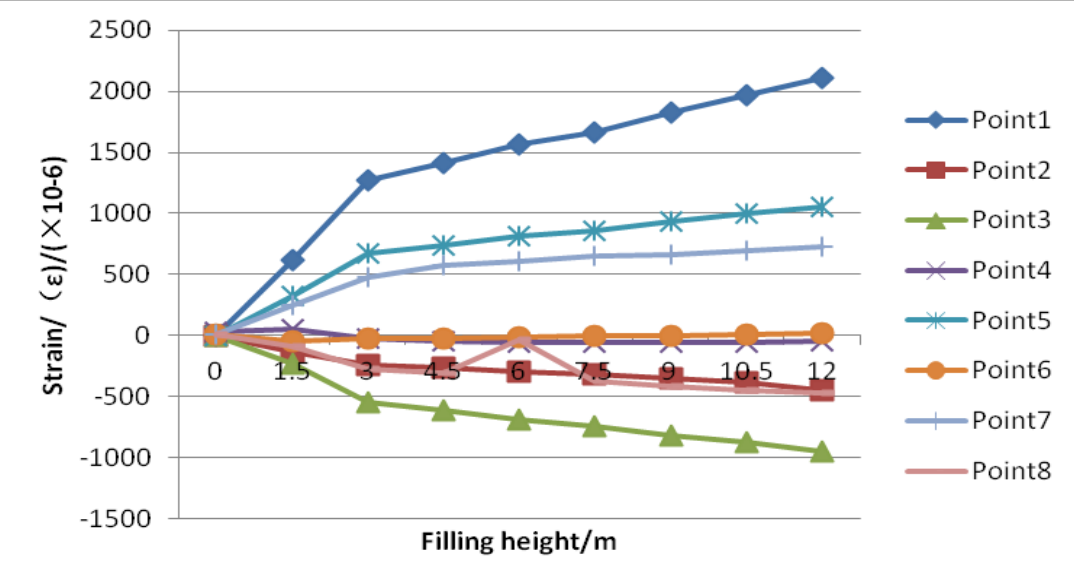

Figure 6. Inner stress curve of strain-filling height under axial loading

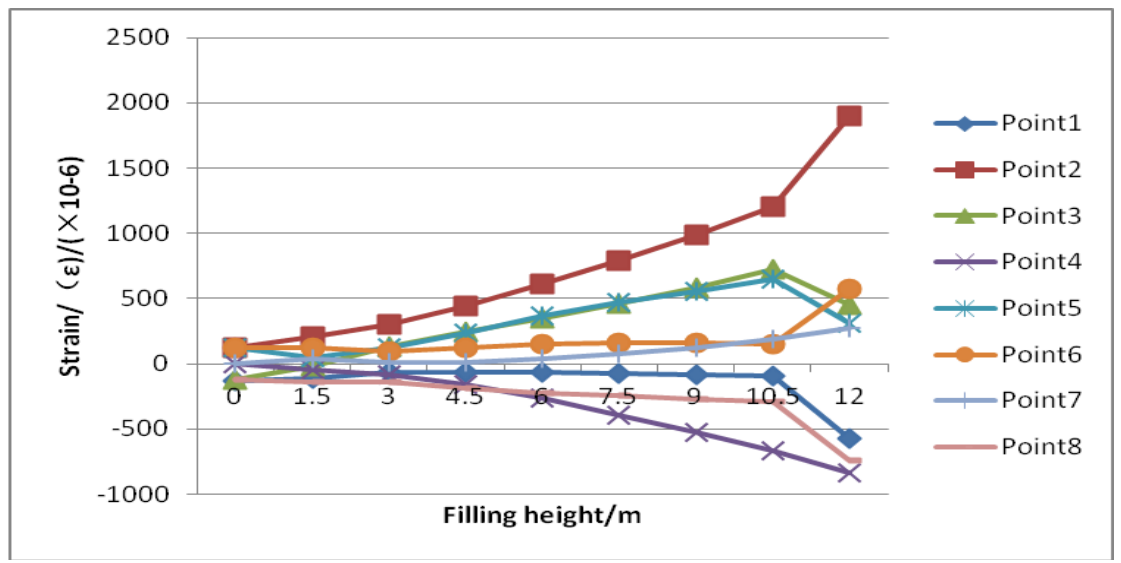

Figure 7. Inner stress curve of strain-filling height under eccentric loading 


\subsection{Stress analysis for inner side of FRPM pipes under eccentric loading}

Figure 5(b) and Figure 7 indicate the actual strain and stress of the culvert under the eccentric load.

(1) The strains of the bias load and the axial load of each measuring point increase with the height of filling [24]. The circumferential stress and strain at the top of the tube (point 1) reaches their maximum, which values are $1898(\varepsilon) /$ $\left(\times 10^{-6}\right)$ and $6092 \mathrm{kPa}$, respectively.

(2) As shown in Figure 7, the height of filling reaches $10.5 \mathrm{~m}$, the strain of measuring points 3 and 5 inside culvert drop. The growth trends of circumferential strain and stress at measuring points 4 and 7 keep unchanged, and the growth trends of points 2, 6, 1 and 8 increase.

(3) Test results indicate that when the partial load is larger, the culverts are more prone to side shifting and uneven deformation. Particular attention should be paid to protect the pipe culvert in construction and service phase.

\subsection{Analysis of earth pressure around FRPM pipe culvert}

The earth pressure change of the culvert fill layer is shown in Figure 8 and Figure 9. The change curves of earth pressure increase with filling in either axial or eccentric loading conditions. The earth pressure at measuring points 7 (top of tube) is far greater than the other points, so it should be considered especially in the design phase.

Moreover, Figure 8 shows clearly that the additional stress caused by the construction load and stiffness difference when the filling height is low. When soil reaches a certain height $(3 \mathrm{~m})$, however, the stress redistribution produce soil arching effect, and the top of the culvert stress and strain growth trend slowed down. In Figure 9, when filling at a certain height (6m), the stress and strain at the top of the culvert growth trend accelerate under the eccentric load, so one should pay more attention to the soil pressure at the top of the pipe under eccentric load and high filling.

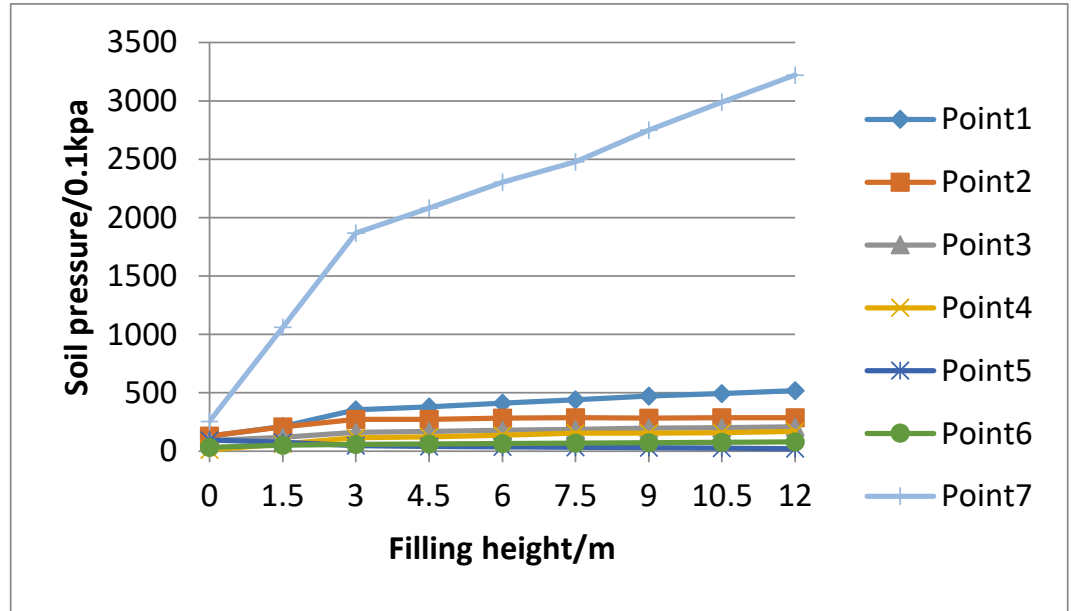

Figure 8. Distribution of earth pressure under axial load

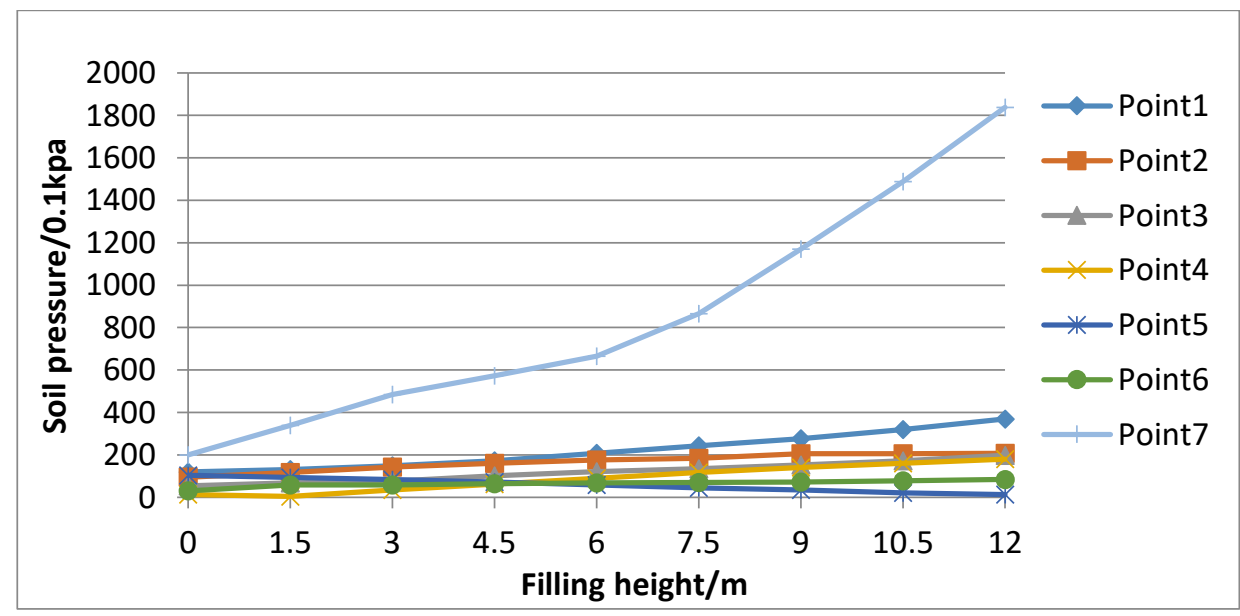

Figure 9. Distribution of earth pressure under eccentric load 


\section{Conclusions}

Model test on mechanical properties of FRPM culvert was performed with filling by layers and loading by jack to simulate real constructing course. Meanwhile, the foil gauges, earth pressure cells and deformation measuring instruments at feature points are arranged to study and analyzed the force characteristics of FRPM, earth pressure around the culvert and deformation of the pipe culvert. As a result of the indoor test simulating of high embankment, the strain, stress and earth pressure around FRPM pipe culvert are determined, and the following general conclusions can be drawn:

(1) The stress of FRPM pipe culvert increases nonlinearly with the increasing height of filling. Under axial loading, the stress and strain inside the culvert distribute symmetrically about the basic axis, grow slowly, and the maximum soil pressure is on the top of the pipe. When the filling height reaches a certain height $(3 \mathrm{~m})$, the changing trend becomes rapidly. Under the eccentric loading, the stress and strain inside the pipe increase gently, but when the filling height reaches a certain height $(10.5 \mathrm{~m})$, the stress and strain increase quickly, the maximum soil pressure appears on the top of the pipe.

(2) The strains of the bias load and the axial load of each measuring point increase with the height of filling. The circumferential stress and strain at the top of the tube (point 1) reaches their maximum, which values are 1898 ( $\mathcal{E}$ )$/\left(\times 10^{-6}\right)$ and $6092 \mathrm{kPa}$, respectively. When the height of filling soil reaches $10.5 \mathrm{~m}$, the strain of points 3 and 5 inside culvert decreases. The growth trends of circumferential strain and stress at measuring points 4 and 7 keep unchanged, and the growth trends of points 2, 6, 1 and 8 increase.

(3) In each condition, the stress and strain at the top of culvert inside (point 1) obtain the maximum value, where the FRPM pipe culvert is in the damage and weak region. When the filling height is low, the additional stress caused by construction load and stiffness difference have an adverse effect on stress the internal pipe culvert, especially the eccentric load condition, so more attentions should be paid to protect the culvert.

(4) The hoop deformation is at $14.58 \mathrm{~mm}$ which is well within the $5 \%$ deflection $(25 \mathrm{~mm})$ specified by ASTM D2412.

(5) Test results indicate that when the partial load is large, the culverts are more prone to side shifting and uneven deformation. Particular attention should be paid to protect the pipe culvert in construction phase and operation phase.

This paper focused on the stress, strain and deflection for the glass fiber reinforced plastic mortar pipes culvert with high filling performed through model test on mechanical properties of FRPM culvert. In spite of considerable efforts given in this paper, there are still some unexplored issues whose accomplishments can be considered for the future studies. The most important issues which have not been addressed can be itemized as below: The field performance of FRMP pipe under normal live-load conditions and service train loads would be investigated. In addition, the fatigue performance of FRMP and damage propagation among different layers through theoretical and experimental studies methods would be processed in next steps.

\section{References}

1. ASTM. D2412, "Standard test method for deformation of external loading characteristics of plastic pipe by parallel plate loading," Philadelphia: American Society of Testing and Materials, 2011.

2. ASTM. D3171-11, "Standard test methods for constituent content of composite materials," Philadelphia: American Society of Testing and Materials, 2011.

3. ASTM. D3517, "Standard specification for fiberglass (glass-fiber-reinforced thermosetting-resin) pressure pipe," Philadelphia: American Society of Testing and Materials,2011.

4. Hawa A, Abdul Majid MS, Afendi M, et al. , "Burst strength and impact behaviour of hydrothermally aged glass fibre/epoxy composite pipes," Mater Des, vol.89, pp.455-64. 2016

5. Kaveh Arjomandi and Farid Taheri, "A new look at the external pressure capacity of sandwich pipes," Marine Structures, vol. 24 , no. 24 , pp. 23-42, 2011

6. J.Z. Chen, Z Li, SR Zhu, ZQ Li and YL Kong, "Prediction of long-term properties of fiberglass pipe based on the shift factors method," Adv Mater Res, vol.48, pp.411-415,2013

7. F.J.C. Del Vecchio, JML Reis and HS Da Costa Mattos, "Elasto-visco plastic behaviour of polyester polymer mortars under monotonic and cyclic compression ," Polymer Testing, vol.35, pp.62-72,2014

8. H. Faria and RM Guedes, "Long-term behavior of GFRP pipes: Reducing the prediction test duration," Polymer Testing, vol.29, no.3, pp.337-345,2010

9. M. Farshad and A. Necola, "Effect of aqueous environment on the long-term behavior of glass fiber-reinforced plastic pipes ,"Polymer Testing, vol.23, no.2, pp.163-167,2004 
10. J.K. Jeya Palan, and eta, “Analysis and design of RPM and other composite underground pipelines," Journal of Transportation Engineering, vol.115, no. 3, pp. 219-231, 1990

11. N.J. Jin, H. G. Hwang, J. H. Yeon, "Structural analysis and optimum design of GRP pipes based on properties of materials," Construction and Building Materials, vol.38, pp. 316-326, 2013

12. C Kaynak, E.S. Erdiller, L Parnas and et al, "Use of split-disk tests for the process parameters of filament wound epoxy composite tubes," Polymer Testing, vol.24, no.24, pp.648-655,2005

13. Y.G. Lee, S.H. Kim, J. S. Park and et al, "Full-scale field test for buried glass-fiber reinforced plastic pipe with large diameter," Composite Structures, vol.120, pp.167-173,2015

14. Herve Ouellette and B.jay Schrock, "Rehabilitation of sanitary sewer pipelines," Transportation Engineering Journal of ASCE , vol. 107, no. 4, pp. 497-513, 1981

15. J.S. Park, W.H. Hong, W Lee and et al, "Pipe stiffness prediction of buried GFRP flexible pipe," Polymers \& Polymer Composites, vol.22, no.1, pp.17-24,2014

16. A.K. Roy and S.W. Tsai , "Three-Dimensional effective module of orthotropic and symmetric laminates," Journal of applied mechanics, vol.59, no.1, pp.39-47,2012

17. MCS Ribeiro, JML Reis, AJM Ferreira and AT Marques, "Thermal expansion of epoxy and polyester polymer mortars-plain mortars and fiber-reinforced mortars," Polymer Testing, vol.22, pp.849-857,2003

18. Roham Rafiee, "On the mechanical performance of glass-fibre-reinforced thermosetting-resin pipes: A review," Composite Structures, vol.143, pp.151-164,2016

19. Roham Rafiee and Ali Amini, "Modeling and experimental evaluation of functional failure pressures in glass fiber reinforced polyester pipe,"Computational Materials Science, vol.23, no.96, pp.579-588,2015

20. Roham Rafiee and Farshid Reshadi, "Simulation of functional failure in GRP mortar pipes ," Composite Structures, no.113, pp.155-163,2014

21. Ying Wang, Jinglan Deng, Jihui Wang and Anxin Ding, "Finite element analysis and application of ring stiffness of FRP pipe ,"FRP / composites, no.11, pp.16-20,2014

22. Lei Xu, Jie Liu, Zhicai Ye and Qingwen Ren, "Analysis of influence factors of buried GRP pipe seismic response ," FRP / composites, no.6, pp.57-63,2012

23. M Xia, H Takayanagi and K Kemmochi, "Analysis of multi-layered filament-wound composite pipes under internal pressure," Composite Structures, vol.53, no.4, pp.483-491,2001

24. S.J. Yoon, "Prediction on the structural behavior of GRP pipe (u2400 mm) buried underground," Research Institute of Science and Technology, 2013 